\title{
A INFLUÊNCIA CORBUSIANA PRESENTE EM 3 OBRAS DE OSCAR NIEMEYER NA DÉCADA DE 30
}

Juliana Barreto da Silva, Fabrícia Dias da Cunha de Moraes Fernandes Borges.

Discente na Universidade do Oeste Paulista - UNOESTE, Curso de Arquitetura e Urbanismo, Presidente Prudente,

SP.

E-mail:

barretojuliana@live.com

\section{RESUMO}

A presente pesquisa visa analisar 3 obras do arquiteto Oscar Niemeyer referente à década de 1930, que diz respeito à influência corbusiana apresentada por ele. As discussões envolveram a apresentação de cada um dos cinco pontos da Nova Arquitetura difundidos por Le Corbusier, retomados por Lucio Costa e que estão presentes na obra de Oscar. Além disto, revelar as decisões do arquiteto, seu discurso e métodos que, introduzidos por Le Corbusier e presente em seus edifícios, enfatizam sua presença relevante no contexto de exploração da carreira e formação de Oscar Niemeyer. A metodologia constou através de estudos de caso e análises a partir de referencial teórico específico e produzido pelos próprios arquitetos e que se refere ao período abordado em estudo. Dessa forma, pode-se concluir que o artigo a seguir é um gatilho para iniciar nesse vasto tema acerca de referências históricas e do nosso desenvolvimento enquanto arquitetos em busca do método projetual que melhor nos represente e satisfaça.

Palavras-Chave: Oscar Niemeyer, Le Corbusier, Lucio Costa, nova arquitetura, movimento moderno

\section{THE CORBUSIAN INFLUENCE PRESENT IN 3 WORKS OF OSCAR NIEMEYER IN THE 30'S}

\begin{abstract}
The present research aims to analyze 3 works of the architect Oscar Niemeyer refering the decade of 1930, which concerns the corbusian influence present by him. The discussions involved the presentation of each of the five points of the New Architecture published by Le Corbusier, taken up by Lucio Costa and present in the Oscar's work. In addition, reveal the architect's decisions, his speech and methods that, introduced by Le Corbusier and present in its buildings, emphasize its relevant presence in the context of exploration of the career and formation of Oscar Niemeyer. The methodology consisted of case studies and analyzes based on a specific theoretical framework and produced by the architects themselves, which refers to the period studied. In this way, it can be concluded that the following work is a trigger to start in this vast theme about historical references and the development of each one of us as architects in search of projectual method that best represent us and satisfies.
\end{abstract}

Keywords: Oscar Niemeyer, Le Corbusier, Lucio Costa, new architecture, modern movement ] 


\section{INTRODUÇÃO}

Le Corbusier é considerado um dos precursores do movimento moderno no que se refere à arquitetura, que eclodiu no século XX. Buscava trabalhar um repertório formal que se adequasse as novas tecnologias recém-surgidas, principalmente vidro e concreto armado, e difundia os cinco pontos da arquitetura moderna'.

Formulados em 1926, esses cinco pontos orientariam e definiriam o repertório das edificações, evidenciando a importância da tecnologia, seu resultado plástico inevitável e a relação direta com a questão da paisagem (HARRIS, 1987).

No Brasil, mesmo que timidamente, esses preceitos começaram a surgir, primeiro em São Paulo e depois no Rio de Janeiro, este último mais precisamente após a década de 1930. Havia a necessidade de criar um estilo original, sintetizando o racionalismo internacional à tradição local existente em nosso território.

Neste processo, aquele que se destacou no que se refere à produção de uma arquitetura moderna no país foi o arquiteto carioca Oscar Niemeyer, que naquele período acabara de ingressar na Escola de Belas - Artes do Rio, dirigida por um curto espaço de tempo pelo arquiteto Lucio Costa, mas que foi suficiente para que os dois criassem laços e viessem a trabalhar juntos mais tarde.

Em 1936, o ministro da Educação e Saúde do Rio de Janeiro, Gustavo Capanema, designa Lucio Costa para projetar a sede de seu ministério, após descontentamento com o resultado de um concurso para a elaboração do mesmo ${ }^{2}$. Foi nessa ocasião que, por indicação de Lucio, Capanema convida Le Corbusier para vir ao Brasil, sob pretexto de palestrar, e projetar uma universidade ${ }^{3}$ na

'Os Cinco Pontos da Nova Arquitetura são: planta livre (através de uma estrutura independente permite a livre locação das paredes, já que estas não mais precisam exercer a função estrutural); fachada livre (resulta igualmente da independência da estrutura, assim, a fachada pode ser projetada sem impedimentos); pilotis (sistema de pilares que elevam o prédio do chão, permitindo o trânsito por debaixo do mesmo); terraço jardim (transformando as coberturas em terraços habitáveis, em contraposição aos telhados inclinados das construções tradicionais) e janelas em fita (também consequência da independência entre estrutura e vedações, se trata de aberturas longilíneas que cortam toda a extensão do edifício, permitindo iluminação mais uniforme e vistas panorâmicas do exterior). Foram publicados em 1926 na revista francesa L'Espirit Nouveau, porém já eram implícitos no esquema Dom-ino de 1914 no qual se separava funcionalmente o suporte da vedação. (POLIZZO, 2011, p.92)

${ }^{2}$ Anunciados os vencedores do concurso, em outubro de 1935, e consumada a sua anulação, em 1936, em manobra exaustivamente abordada na historiografia do moderno brasileiro, Gustavo Capanema solicita a Lucio Costa uma versão alternativa à proposta de Archimedes Memória, ganhador do primeiro lugar, por considerá-la insatisfatória. (BRUAND, 1997, p. 81-93)

${ }^{3}$ Decidiu-se que Le Corbusier seria convidado como arquiteto consultor, não só para opinar sobre os planos do futuro ministério, bem como para elaborar o primeiro esboço da Cidade Universitária, que se pretendia construir no Rio de Janeiro, porém esse projeto nunca saiu do papel. '(COSTA, 1995)

cidade (NIEMEYER, 2005). Mas além da Cidade Universitária, ele propõe um novo projeto para o Ministério da Educação e Saúde (MES). 
Nesta ocasião, Oscar Niemeyer que colaborava no ateliê de Lucio Costa pôde conhecer melhor Le Corbusier, e durante 15 ou 20 dias o acompanhou como desenhista (NIEMEYER, 2005). Lucio a essa altura já havia organizado sua equipe de projeto, composta por Carlos Leão, Affonso Reidy, Jorge Moreira e Ernani Vasconcelos, porém quando Niemeyer aparece com alguns croquis baseados no projeto de Corbusier, resolvem adotar sua proposta, e o arquiteto carioca passa a fazer parte da comissão e ganhar certo prestígio.

Segundo Lucio Costa (1995), além dos planos para a Universidade, as palestras e o traçado fundamental do Ministério, Le Corbusier haveria nos deixado uma dádiva, em quatro semanas de estadia no Brasil foi responsável por aflorar o gênio incubado de Oscar.

Após a realização do projeto do Ministério e, em consequência, o reconhecimento a nível internacional, Niemeyer inicia um trabalho muito rico no que diz respeito a arquitetura moderna do país, ligada à tradição e à cultura nacional e fortemente filiada a arquitetura de Corbusier (FRAGA, 2006). Seu trabalho, no que se refere ao período entre o projeto do MES até o início da década de 1940 é, mesmo que tímido - comparado a sua produção após o projeto do Conjunto da Pampulha ${ }^{4}$-, uma demonstração da influência corbusiana, da nova arquitetura e da busca por brasilidade.

Procurando apresentar, de forma objetiva, características que refletem essa influência em suas obras, a presente pesquisa buscou analisar três projetos de Oscar Niemeyer, destacando os pontos da Nova Arquitetura escritos por Le Corbusier, presente na composição de cada uma delas.

\section{METODOLOGIA}

Esta pesquisa foi realizada através de estudos de caso e análises, resultando na obra produzida por Oscar Niemeyer na década de 1930. Para isto foram utilizadas bases de dados digitais e levantamento de referenciais teóricos específicos, como Carlos Eduardo Comas, além de textos e publicações dos próprios arquitetos presentes na pesquisa, Oscar Niemeyer, Lucio Costa e Le Corbusier. Esse mesmo conteúdo ainda é explorado e disponibilizado por plataformas institucionais e digitais oficiais de arquitetura, tais como: Fundação Oscar Niemeyer (niemeyer.org.br), Portal Vitrivius (vitruvius.com.br), Archdaily (archdaily.com.br) e AU Pini (au.pini.com.br)

${ }^{4} \mathrm{O}$ Conjunto da Pampulha, em Belo Horizonte, foi projetado por Oscar Niemeyer, sob encomenda do prefeito Juscelino Kubitschek, e construído entre 1942 e 1944. (Fundação Oscar Niemeyer) 


\section{DISCUSSÃO \\ OSCAR NIEMEYER E LUCIO COSTA}

Segundo biografia disponibilizada pela Fundação Oscar Niemeyer (2017), Oscar Ribeiro de Almeida Niemeyer Soares Filho nasceu em 1907, na cidade do Rio de Janeiro. Passaram-se 22 anos até que ingressasse na escola de arquitetura e se aproximasse do trabalho de Lucio Costa, passando a frequentar o ateliê do arquiteto, lugar onde lhe diziam que "encontraria o caminho da boa arquitetura" (NIEMEYER, 2005). E, segundo o que sabemos sobre arquitetura até hoje, provavelmente fora ali que o tenha encontrado.

\section{MINISTÉRIO DA SAÚDE E EDUCAÇÃO}

O projeto para o Ministério da Saúde e Educação foi idealizado no ano de 1936 pelo a pedido do ministro Gustavo Capanema ao arquiteto Lucio Costa, que montou uma equipe com alguns arquitetos cariocas, entre eles, Oscar Niemeyer, recém-formado, mas que se destacava pelo seu traçado único. De passagem ao Brasil, Le Corbusier propôs alguns projetos para a construção do edifício bem no centro da cidade, e foi com base nessas propostas que Oscar Niemeyer se atreveu a rabiscar alguns croquis, que foram fielmente adotados pela equipe do projeto.

Segundo Bruand (1997), o projeto do Ministério se valoriza pelas condições de dinamismo e leveza e a forte integração entre arquitetura, paisagismo e artes plásticas. 0 edifício inaugura uma nova arquitetura, resultante da influência de vertentes internacionais em conjunto das experiências da escola carioca em sua busca pela reinterpretação da arquitetura local.

Através dos cinco pontos de Le Corbusier, podemos analisar como o partido segue de modo fiel às suas recomendações. Os dois primeiros aspectos a serem observados são a planta e a fachada livre. No edifício, a estrutura independente utilizada permite a livre locação das paredes, assim como a fachada pôde ser projetada sem nenhum impedimento de motivo estrutural. Os pilotis também são utilizados por ele, elevando o prédio do chão e permitindo o livre trânsito de pessoas. Em busca de liberar esse espaço no solo e trazer a relação do público ao privado. $O$ arquiteto também trabalha com o terraço jardim, que transfere essa área para cima do edifício, permitindo total permeabilidade.

$\mathrm{Na}$ janela horizontal, como nos outros pontos de sua arquitetura, Le Corbusier buscava certa justificativa ambiental, o que cabe totalmente ao projeto do Ministério, cuja proposta inicial de Le Corbusier baseou o resultado final idealizado pelos arquitetos, que buscaram otimizar o comportamento ambiental do edifício, desde sua orientação até a proteção das janelas (MELENDO, 2004), adicionando o brise-soleil horizontal móvel - uma novidade até mesmo para os experimentos de Le Corbusier (MACEDO, 2012), resultando em condições perfeitas de iluminação e ventilação.

Apesar de se tratar de um período referente à produção moderna na arquitetura, em relação à sua posição quanto a essa obra em questão, no que diz respeito à influência de Le Corbusier encontrada, Niemeyer (2005, p. 149) afirma:

Nunca considerei a sede do Ministério da Educação e Saúde como a primeira obra de arquitetura moderna brasileira, mas sim um exemplo da arquitetura de Le Corbusier, um arquiteto estrangeiro que esclareceu para todas as razões do movimento moderno, dos pilotis, da estrutura independente, do painel de vidro, e isso foi muito importante para a 
nossa arquitetura.

Para Niemeyer era claro que a arquitetura de Le Corbusier era de extrema importância, não somente seu método de trabalho presente nos cinco pontos, mas sua preocupação com problemas formais e a valorização dos elementos locais, que seriam cruciais para atingir a liberdade projetual que tanto almejava.

Segundo Niemeyer (2005), esses aspectos e a sua atuação inesperada no desenvolvimento do projeto do Ministério só abriram um leque de possibilidades para que ele buscasse a solução arquitetônica e pudesse traçar o caminho na busca pela sua verdadeira e correta arquitetura. Arquitetura que nunca se veria igual, que valoriza o contexto urbano e o meio ambiente, o que descreve aquilo que vemos ser produzido no atual cenário da arquitetura contemporânea.

\section{PAVILHÃO DO BRASIL NA FEIRA MUNDIAL DE NOVA YORK}

A construção do Pavilhão do Brasil na Feira Internacional de Nova York de 1939 também foi objeto de um concurso, no qual Lucio Costa foi o vencedor. Já conhecedor do desempenho de Oscar, que vencera em segundo lugar, Lucio decidiu convidá-lo para que idealizassem, em conjunto, uma terceira proposta que resultou no projeto final (COMAS, 2010).

Em um texto sobre o Pavilhão, Lucio Costa justifica a presença de Niemeyer: Levei o Oscar comigo para Nova York a fim de elaborarmos novo projeto para o Pavilhão do Brasil na Feira Mundial de 1939, porque foi depois da vinda de Le Corbusier em 36, por iniciativa minha, que a sua criatividade se revelou subitamente, com grande força inventiva; entendi então que era o momento de ele desabrochar e ser reconhecido internacionalmente. (COSTA, 1995, p. 190).

A obra do Pavilhão se deu logo em seguida ao projeto do MES, que, como vimos, foi fortemente influenciado pela presença corbusiana. Porém no Pavilhão ela se deu de maneira pontuada, rompendo com a forma pura, mas aproveitando do potencial plástico e expressivo. A questão principal era a liberdade formal, e esse projeto é o melhor representante do momento em que Niemeyer inicia um processo de emancipação das formas encurvadas, que para Le Corbusier, se limitavam ao campo pictórico (COMAS, 2010).

Os princípios da nova arquitetura continuaram a ser empregados, como podemos detectar na presença da planta e o térreo livre, este segundo não eleva o jardim, pois Niemeyer o transporta para o interior do terreno, seguindo a marquise curva do edifício que, sustentada pelos pilotis, expressa o vocabulário formal corbusiano que Niemeyer interpreta de forma menos purista possível, sem limitações. O mezanino, permeável e cheio de sinuosidade, resultado da estrutura independente, segue o traçado do terreno que, de um lado é vedado para a rua, e do outro é visualmente aberto para o jardim, permitindo total integração visual com a paisagem graças ao emprego do vidro em praticamente toda fachada.

A disposição dos pilotis também atua demarcando o acesso principal do edifício, que implantado em situação privilegiada - entre o entroncamento de duas avenidas principais, e com vistas para o Rio Flushing -, era de passagem obrigatória e objeto de admiração de todos os visitantes da feira. O esqueleto estrutural do Pavilhão foi constituído de pilares de aço revestidos, diferente do usualmente empregado até então, com as grandes descobertas 
acerca do uso do concreto armado (COMAS, 2010). A questão estrutural foi uma das grandes premissas desse projeto, que possibilitado pelo esquema corbusiano de planta livre atrelado ao aperfeiçoamento da tecnologia, propiciou uma grande flexibilização da malha, que se adapta ao terreno, suporta os balanços da laje e resulta em uma forma original e inovadora, que expressa a brasilidade tão almejada pelos arquitetos.

\section{RESIDÊNCIA FRANCISCO PEIXOTO}

A Residência de Francisco Peixoto foi a primeira construção considerada moderna da cidade de Cataguases, Minas Gerais, em 1940. Apesar de ser um pouco tardia após a produção do Conjunto da Pampulha -, ela traz algumas características remanescentes do período passado ao lado de Lucio Costa e a relação aos princípios corbusianos adotados pelo arquiteto.

Apesar do Conjunto da Pampulha ter sido a obra que marca o início do seu traço arquitetônico (NIEMEYER, 2005), é importante analisar o que foi produzido durante esse meio tempo, pois são características pontuais que guiaram o rumo da sua identidade projetual. O que pode ser visto da Residência Francisco Peixoto é algo que, partindo da influência de Lucio Costa, desde o projeto do Pavilhão do Brasil, é a busca pela regionalidade, e que no caso dessa casa, possui elementos que caracterizaram a arquitetura colonial do país (MACEDO, 2012).

A casa está situada em um terreno profundo, entre o Rio Pombae e uma avenida de grande movimento. A forma foi disposta em formato de "L" voltado para os fundos, ocupando toda largura do terreno, fechado em uma fina cobertura de pé direito duplo com vista para o rio. Junto à entrada, a casa é elevada acima da garagem com o emprego de pequenos pilotis, cujo mesmo nível se encontra os ambientes de serviço. A varanda também se abre por panos de vidro, que remarca essa característica de permeabilidade visual da obra. Bem setorizada, nota-se a diferença entre os ambientes pelos níveis internos. Como quem abraça o entorno, o edifício surge como uma maneira bastante simplória de solucionar o programa considerando suas pré-existências.

Essa casa é considerada um dos raros exemplos da obra de Oscar que confunde telhados cerâmicos com os volumes puristas corbusianos (MACEDO, 2012), ou seja, essa mescla de tradição e modernidade, assumindo o caráter original que tanto suas obras imprimem. Apesar da pouca relação com os princípios corbusianos na concepção final deste edifício, pode-se observar uma conformidade da produção do arquiteto desde o projeto do MES, que é a relação entre o espaço interno e externo valorizando o conjunto total da obra. Em todos os casos, esta se deu através da permeabilidade visual, das formas livres e do paisagismo, e grande parte disso é resultado das influências que teve ao longo dos anos.

Como o próprio Oscar afirmou, seu trabalho girava em torno de procurar a "solução arquitetônica" (NIEMEYER, 2005, p.105), encontrá-la, desenhá-la e escrever um texto explicativo sobre a mesma. Se ao lê-lo seus argumentos soam frágeis demais, ele volta a projetar, até que o conjunto final o satisfaça. Ou seja, as influências que sofreu ao longo da década de 1930 serviram para solidificar sua postura enquanto arquiteto e procurar soluções além do que já havia sido criado. Se ele pudesse aperfeiçoar uma técnica, ele a faria, até que esta se adequasse ao contexto do projeto em execução. Assim ele fez no MES, em Nova York e na cidade de Minas Gerais. 


\section{CONCLUSÃO}

Conclui-se com o presente trabalho que a influência corbusiana na produção arquitetônica de Oscar Niemeyer foi de extrema importância para que aflorasse e desenvolvesse sua identidade, mas que esse contato nunca teria acontecido sem a forte presença do arquiteto Lucio Costa, que desde cedo enxergou em Oscar o gênio que ele era.

Seu traço se consolidou, não somente a partir dos princípios puristas, mas também por um caráter brasileiro, buscado não somente por ele, mas diversos arquitetos cariocas que surgiram naquele período, determinados em construir uma identidade brasileira original na arquitetura. Ademais, sua obra se destaca pela eficiente união entre beleza, função e estrutura, agradando não somente entendedores do assunto, mas o mundo todo.

\section{REFERÊNCIAS}

HARRIS, E. D. Le Corbusier: riscos brasileiros. São Paulo: Nobel, 1987.

NIEMEYER, O. Minha arquitetura: 1937 - 2005. Rio de Janeiro: Revan, 2005, 2a edição.

POLIZZO, A. P.; Kamita, J. M. A estética moderna da paisagem: a poética de Roberto Burle Marx. Rio de Janeiro, 2010. 173p. Dissertação de Mestrado - Departamento de História, Pontifícia Universidade Católica do Rio de Janeiro.

BRUAND, Y. Arquitetura Contemporânea no Brasil. São Paulo: Perspectiva, 1997 (3a ed.)

COSTA, L. Lúcio Costa: registro de uma vivência. São Paulo, Empresa das Artes, 1995.

FRAGA, C. A. S. Museus, pavilhões e memoriais: a arquitetura de Oscar Niemeyer para exposições. Dissertação de mestrado apresentada no Programa de Pesquisa e PósGraduação em Arquitetura. Orientação: Carlos Eduardo Comas. UFRGS, 2006.

MELENDO, J. M. A. Da janela horizontal ao brise-soleil de Le Corbusier: Análise ambiental da solução proposta para o Ministério da Educação de Rio de Janeiro. Arquitextos, São Paulo, ano 05, n. 051.02, Vitruvius, 2004 <http://www.vitruvius.com.br/revistas/read/arquitextos/05.051/554/pt>.

MACEDO, Oigres Leici Cordeiro de. Construção Diplomática, missão arquitetônica: os pavilhões do Brasil nas feiras internacionais de Saint Louis (1904) e Nova lorque (1939). Tese de doutorado apresentada ao Programa de Pós-Graduação em Arquitetura da USP. Orientação: Hugo Segawa. São Paulo, 2012.

COMAS, C. E. Feira Nova York World, de 1939: O Pavilhão Brasileiro. Arqtexto 16 (Porto Alegre: UFRGS, 2010). Disponível em: <https://www.ufrgs.br/propar/publicacoes/ ARQtextos/pdfs_revista_16/03_CEC.pdf.> 